\title{
Evolutionary aspects of Parvovirus B-19V associated diseases and their pathogenesis patterns with an emphasis on vaccine development
}

\author{
Piyanki Das $^{1} \cdot$ Koustav Chatterjee $^{1} \cdot$ Nabanita Roy Chattopadhyay $^{1} \cdot$ \\ Tathagata Choudhuri ${ }^{1}$
}

Received: 21 February 2019/Accepted: 15 March 2019/Published online: 26 March 2019

(C) Indian Virological Society 2019

\begin{abstract}
Parvovirus B-19, a single human pathogenic member of the Parvoviridae family with it's small ssDNA and non-enveloped structure, is known to cause diseases in erythroid progenitor cells. But a wide range of clinical association of this virus with cells of non-erythroid origins has recently been discovered and many of those are being investigated for such association. Higher substitution rates in due course of evolution has been suggested for this cellular tropism and persistence. In this report, we have summarized the different disease manifestations of B-19 virus and have tried to find out a pattern of pathogenesis. Finally, we have focused on the vaccination strategies available against B-19 virus to correlate these with the mechanisms involved in various diseases caused by this virus.
\end{abstract}

Keywords Parvovirus B-19 (B-19V) · Disease manifestations - Productive and non-productive mechanisms · Vaccine development

\section{Introduction}

Humans are exposed to lots of different viruses ubiquitous in nature, and a large portion of them are unidentified, undefined, and unclassified. Though ssDNA viruses form a diverse pool of pathogenic entities, pathogenicity towards humans is comparatively rare. These viruses constitute a very small family in the viral world probably due to their

Tathagata Choudhuri

tathagata.choudhuri@visva-bharati.ac.in

1 Department of Biotechnology, Visva Bharati Santiniketan, Siksha Bhavana, Bolpur, West Bengal 731235, India receptor specific tropism, small genomic structure, and for the molecular mechanisms inside the host used for viral replication [52]. Parvovirus B-19 is one of the less described members of this group, and is considered as less dangerous to be worried about. This is the only human pathogenic member of this family. Cultivation of virus is difficult in vitro and only a few available human cell lines can be used to know the mechanism and pattern of pathogenesis [23]. Based on the available reports on B-19 diseases association and its' mechanistic study we have set our goal for the following factors. Firstly, detailed review of literature concerning about the associated clinical conditions as this virus is associated with several situations except the commonly known slapped chick syndrome that has to be identified and described properly to limit its' emergence. We will be analyzing different diseases and clinical conditions in humans which are associated with B-19 viral infections. Secondly, we will try to find out the host-virus cross-talk in these afore mentioned conditions. Finally, the study will focus on revealing the untouched areas of its therapeutic strategies, especially the vaccine development strategies which need to be explored in detail. The overall review of will be helpful for determining how much attention we need to pay on this infectious agent to cope with the associated diseases.

\section{Evolutionary aspects of B-19 virus}

B19 shows horizontal gene transfer between acutely infected individuals and three basic genotypes are maintained by this virus, as detected till date. Genotype 1, with its subtypes $1 \mathrm{~A}$ and $1 \mathrm{~B}$, is mainly found in USA, Europe and other such Western countries. Genotype 3, with its subtypes $3 \mathrm{a}$ and $3 \mathrm{~b}$, is found in South America and Africa. 
Interestingly, genotype 2 is found to be restricted in individuals of Western countries born before early 1970s. These genotypes vary in their nucleotide sequences: about $10 \%$ to a maximum of $14 \%$; and the subtypes vary by around $5 \%$. But they show similar functional, structural, immunological, and serological characteristics [37, 49].

In search for their persistence and incidence patterns, scientists have found a very high rate of nucleotide substitutions which is comparable to the substitution rates of ssRNA viruses. On average, $1-2 \times 10^{-4}$ substitutions/site/ year may be seen. This significantly high mutation rate might contribute to an efficient adaptive nature of the virus, and thus, for their wide variety of cellular tropism in humans. Therefore this virus is thought to be evolved rapidly, with an estimate of an ancestor to date back in early 19th century. But a recent literature shows the existence of B19 in the human population present around 7000 years ago; and the earliest sample was present around 12.5 thousand years ago [36]. Therefore it can be inferred that the virus had a much lower mutation rate in its longago ancestors. Though the reason behind the acceleration in the mutation rate is not known, it is inferred that the virus has gone through a rapid change in recent times. This higher substitution rates might affect the virus' tropism for different varieties of host cells, and account for its persistence; thereby affect the vaccination strategies against it.

\section{Disease manifestations of $B-19$ virus}

B-19 virus is mainly known to be associated with the common child hood diseases Fifth diseases or Slapped Cheek syndrome. This disease is commonly cured automatically with mild clinical symptoms in children like fever and body rash, joint pain, swollen gland, headache etc. The specific diseases associations are fifth diseases in children, transient aplastic crisis, persistent anemia, hydrops fetalis, and several other diseases like rheumatoid arthritis, cardiac diseases, neurological problems etc. [20, 46]. This association found sometimes directly with viral pathogenesis and in several cases direct association is not found with the virus rather it triggers the manifestation. Maximum of the diseases are self-curable. Till now everything seems fine but the point of worry comes when the B-19V infection is associated with some clinical conditions like, weak immune system, hematological disorders, pregnancy etc. The outcome and pattern of the B-19V infection is mainly dependent on the host hematological and immunological situations [46]. After the initial symptoms to the appearance of the rashes the physical discomfort seems to disappear and the phase before the rash appearance is mainly contagious. This disease spreads via the school going children through respiratory exposures. There are still no such vaccines against this virus or no promising treatment options avaibable, only normal antibiotic drugs are applied [23]. So next we will examine the relationship status of B-19 with different clinical or health conditions in-search of finding a pathogenic pattern and vaccines.

\section{Hematological crisis}

B-19 infection is specific to erythroid progenitor cells. So blood related disorders should be closely investigated with B-19 correlation. This blood related disorders may be caused solely with the virus or it may be associated with underlying health issues. Severe aplastic anemia may be caused due to B-19 infection without any underneath disease symptoms. The laboratory reports from a 1 years old boy peripheral blood and histopathological test report depicted the presence of thrombocytopenia, leukopenia, hypoplastic bone marrow and later development of pancytopenia and the platelet and myeloid production interference has been observed in this case. Immune suppression therapy has been applied for the patient but precise pathogenetic mechanism has not been cleared [39]. A case report by X H Qian, 2002 shows the presence of B-19 viral DNA in six children with severe aplastic anemia. Two children among them died due to hemorrhage. The rest of the patients were treated properly with horse antilymphocyte globulin, cyclosporine and intravenous immunoglobulin [43]. Now switching over to the focus on the B-19V infection, in case of patients with underlying health issues the scenario is much worse. Patients with different underlying hemolytic anemia, hereditary anemia, immune disorders, hematological malignancies like leukemia, sickle cell diseases, thalassemia can develop transient aplastic crisis, with B-19V infection which can cause a sudden drop of hemoglobin and no reticulocyte production leading to life threatening situations. Several cases reports suggest this hypothesis. Here the virus directly attacks the erythroid progenitor cell production in bone marrow which prevents the production of mature $\mathrm{RBC}$ in blood and many of them did not show any antibody against B-19 probably due to immunocompromised situation and sometimes due to asymptomatic infections. All of these infections are very much common among children $[25,26,47,61]$.

\section{Immunological perspective and HIV}

Patients with weak immune system especially with disturbed cell mediated immunity or HIV patients, leukemia or transplant recipients may develop persistent anemia or pure red cell aplasia. In this case the patient can not clear out the viral infection thus a persistent low level of viral replication is always going on inside the cell and cannot be 
controlled [42]. Particularly if we discuss the interaction of B-19 virus in HIV patients, it can be demonstrated that out of different hematological conditions patients with immune disorders and HIV patients are much more prone to have the viral infection. A report says out of such $17 \mathrm{~B}-19 \mathrm{~V}$ positive patients with blood related disorders, 8 were HIV positive. The age group was of 8.7 years on average. They showed unexplained anemia, thrombocytopenia, eosinophila, bicytopenia, pancytopenia etc. They required prolonged retroviral therapy for complete eradication of the virus even after treatment with immunoglobulin. Different stages of HIV patient show B-19 viral DNA in blood, saliva, urine samples and the detection was done by immunoblot assay and bone marrow cell appearance. The immunogenic response was very low, tested with B-19 antibodies and absence of cell mediated immunity has been observed with abnormal blood parameters. Common IVIG treatment was administered to them [19]. Particularly HIV patients in general shows low B-19 viral titer with chronic anemia in PCR assay and both homo and hetero sexual patients are associated with it $[1,11]$. The virus play little role in the diseases manifestation but the weak immune system and retroviral side effects mainly create an atmosphere of getting B-19 infection and which may additionally help in the development of severe hematological condition in those patients, however the co-association of HIV virus and B-19 virus has not been studied so far. [18, 42]. An interesting report has been found in HIV positive homosexual men (39 years-old) who developed B-19V associated urinary tract infection. The laboratory results depicts the high viral shedding in urinary tract tested from urine samples and low titer in blood sample. The biopsy done from bladder wall sample indicates latent B-19 viral existence in the viral receptor expressing endothelial glomeruli cells in the epithelial lining of kidney and bladder. Such nephritic syndrome has been reported to be associated with sickle cell anemia and in case of immuno compromised patients, this case also supports the symptoms but particularly in this case report with specific high viral titer in renal cells indicates the possibilities the different pathogenesis of the virus with immunological interruption and non- hemolytic association [14].

\section{Pregnancy}

Pregnancy and B-19 infection association is very common scenario but practically there is no maternal screening or preventive care or therapeutic options opted [50]. Even the abortion and miscarriage cases should be considered though the reports are few but sometimes unknown cause or unidentified cases creates dilemma [38] Pregnancy do not effect the viral infection cycle but it can create an environment in which if B-19 virus takes shelter and may cause severe clinical complications. The maternal problems includes fifth diseases, chronic anemia, arthopathy etc. and for the fetus the adverse conditions may include hydroph fetalis or immobility of the fetus, anemic fetus, may have increased blood flow in the cerebral artery which may ultimately causes fetal death [21] It has been noted that having B-19 infection in women is common but when it comes to pregnancy extra care must be taken because though the chance of infection is rational but the nulliparous women are at low risk than any women who is pregnant or already had one or multiple pregnancy indicating the persistent infection of the virus. In terms of the risk the exposure of pregnant women to fifth diseases causes high risk and the gestation week actually determines the severity. 13-20 weeks comes under high risk while the asymptomatic infection may be a threat. Infection in early stage of gestation shows high fetal loss because of the low immune responsiveness compared to the later stage. Though the pathogenesis pattern of the virus in pregnancy is not clear but the infection is transferred vertically from mother to fetus by placenta [22]. B-19 infection causes intrauterine fetal death but the viral pathogenesis inside the uterus is not revealed. After 6/7 week of maternal exposure the fetal infection develops. The detection of the virus from the maternal tissue and fetal tissue samples proves this [16].

\section{Transfusion and transplant donor-recipients risk factors}

Different types of organ and blood and related progenitor cell transplantation is another scenario in which when B-19 virus attack can cause severe health hazards and different types of diseases manifestation mainly chronic anemia and others are hepatitis, cardiac failure etc. This infection may lead to rejection of the transplanted organ or cells and death occurs due to cardiac failure in the infected patients. In transplanted patients infection may occur from 1 week to 3 years after transplantation [17]. The virus is transmitted in these cases from the donor to the recipient through the transplanted organ or products. In other perspective the transplant or transfusion patients are administered with immunosuppressive drugs so their weak immune system acts as favorable environment for the B-19 infection. The problem is associated with the transplant patients and the detection of the B-19 viral $\operatorname{IgG}$, because during the process blood and immunoglobulins are also administered to the host and thus it may give false positive results. So at detection level we should depend on the PCR based analysis. Thus along with the common antibiotic, IVIG treatment elimination of the immunosuppressive drugs may help to build up the host immune system to fight against the virus naturally. Repeated relapse of the infection and 
associated clinical symptoms may occur in transplanted patients so early diagnosis and specific therapeutics should be concerned in this cases. Among organ transplanted patients renal or kidney transplanted patients are reported for having B-19 infection [4, 17, 32]. Not only the transplanted patients, patients having dialysis or several nephritic and kidney related problems are also at high risk. There is no direct cytophathic mechanism for the B-19 virus is available but $\mathrm{P}$-antigen specific infection and expression of NS-1 protein has been demonstrated the role of B-19 virus in injuring cells. [54]. Now if we consider the blood or blood related transfusion cases, an interesting pattern have been noticed in Indian donors. North Indian donor populations are mainly exposed and seropositive for B-19 virus and are naturally immune who were tested with B-19 IgM antibody. This report indicates an epidemiological pattern of the infection depending on geographical location [44]. The main drawback is underneath in the screening guidelines for the pre and post blood/plasma/ organ donation. Except some common pathogens B-19 has not been paid attention to these cases.

\section{Hepatitis/gastro/liver related disorders}

Parvovirus B-19 can be associated with different liver related diseases manifestations. Conditions like increased liver enzymes like transaminase, acute, chronic hepatitis and even complete liver failure are the common clinical scenario with this infection. In case of the chronic form of hepatitis caused by hepatitis C and B virus the B-19 infection can not cause any extra burden to these virus and liver functioning [60] Though the association is very less in percent (4\% approx.) it includes patients from all age group. B-19 hepatitis is more severe in case of children rather than adults, where it can be completely curable [48]. Hepatic liver damage and death has been reported with a large titer of B-19 virus. Some underlying health conditions like animia, haematological disorders etc. and co-infection of other virus causes severe case of hepatitis infected with B-19 virus. Immunocompromised and immunodeficient patients also come under the severity zone for having B-19 virus mediate hepatitis. [34].

The complete mode of the virus in causing various hepatic syndromes has been clearly revealed. The virus does not replicate inside the hepatic cells but it just causes injury and cell death. After proper receptor mediated infection the virus produces nonstructural protein 1 which induces of cycline dependent kinase inhibitor p21/WAF1 leads to G1 phase cell cycle arrest and ultimately Caspase 3/9 induced apoptosis. From immunological mechanistic point of view, due to B-19 infection cytotoxic micro environment is created in liver cells. CD8 cells are derived from bone marrow and liver produces cytotoxic CD8 T cells which activates altered monocyte and macrophages and then secretion of IFN gamma, TNF alpha,Il-2, and reduced IL-1 leads to hepatocyte damage and hepatitis [8].

\section{Neurological scenario}

B-19 infection may associate with several neurological disorders. Main target point is the central nervous system and maximum association found with encephalitis. The neuroimaging and the biochemical analysis cannot be promising for the assessment of the B-19 virus, the PCR and $\mathrm{IgG} / \mathrm{IgM}$ antibody based assay proved the presence of B-19 viral association. Normal encephalitis and B-19 associated encephalitis do not show such significant variation in terms of the clinical symptoms except rash, anemia, arthritis and immuno-compromised situation but these should not be the criteria for the identification of the virus with encephalitis. The initial infection doesn't show any shorts of immune response. The solo detection must be done in case of encephalitis patients. The independent existent of B-19 virus in the brain cells has been found from the different tissues of brain. Intravenous immunoglobulin in combination with steroid found to be promising treatment options currently available. But more or less a report suggests $14 \%$ of patient's death with encephalitis followed by neurological abnormality [7]. The other clinical conditions found are encephalopathy, menengocephalitis etc. A case report of an immuneocompromised women shows B-19 infection from cerebral fluid and blood samples without any B-19 precise clinical symptoms [9]. Thus indicating towards the symptom independent screening and immuno-compromised ones similarly creates an extra burden. The neurological manifestation and B-19 viral association is found as recent era of this viral pathogenesis, yet it has to be studied in depth.

\section{Cardio and respiratory illness}

Parvovirus infection is mainly transmitted via the respiratory secretions and first the virus is known to replicate in the nasal or respiratory tract and spreads to bone marrow, different elytroid precursor cells or endothelial cells in the body by blood. Thus the primary site of the viral infection is the upper respiratory tract region, specifically the nasopharynx. The most common clinical symptoms of B-19V infection is common cold, rashes in the facial region, influenza like symptoms, thus it can be easily demonstrated that the virus may have certain infectious role with different respiratory problems. A study shows out of 156 patients admitted with respiratory problems $5.1 \%$ patients have B-19 viral infection. They showed clinical symptoms like wheezing, fever, cough, bronchiolitis, pharyngitis etc. the platelet and neutrophil count was less 
than normal in those cases. Pneumonia is associated with all these cases [51]. Respiratory problem might be a clinical problem associated with B-19 infection but no such report proves its direct pathological relation with any kind of these diseases. B-19 infection is also reported to be associated with body fluid based effusions like pleural, pericardial effusion. A case report suggests that a 37 years man admitted and diagnosed with pulmonary and pleural effusions without any cardiac complications is having B-19 viral infection but parallely elevated level of brain natriuretic protein (BNP) indicating heart failure. The viral presence was confirmed by PCR assay and increased titer of antibody. An interesting finding is that the patient was exposed to a 3 years old child having B-19 infection. In terms of treatment, they were administered with antibiotic and IVIG (intravenous immunoglobulin) and discharged with complete cure. Association of other complications or pathogenic presence was negative [59]. A diabetic women was reported to have parvoviral pneumonia with several complications like, fever, body rash, chest pain etc. and the patient was tested positive for B-19 parvoviral infection without the association of any other bacterial or fungal pathogens. The B-19 virus was confirmed by PCR assay, IgG analysis from the diffuse bronchial or alveolar fluids. The complete blood count test was not normal for this case. Smoking and intravenous drug association has been observed in these cases with respiratory problems and viral infection which might be a triggering factor for such infection [57]. Direct pathogenic relation has not been confirmed here. Another case report also suggests the association of B-19 virus with pneumonia in a bone transplant patient [45]. Previously it has been described in this review that organ transplanted patients have faced B-19 infection and reports shows of their death due to cardiac failure. Dilated Cardiomyopathy and Myocarditis are the two diseases manifestation related to B-19 infection. But unavailability of direct pathogenic role of the virus provides unrevealed concept. Presence of B-19 viral titer in normal heart tissues and in cardiac patients' heart tissues does not differ much. The host's immunological and other health conditions might determines the fate of B-19 associated clinical symptoms [59]. However direct B-19 infected myocarditis without and other diseases association and co-associated with other cardiotrophic virus has also been reported [3, 24, 33, 53].

\section{Thyroid related autoimmune diseases and malignancies}

B-19 viral infection has recently been identified and linked with several autoimmune diseases and all of them are related to thyroid related disorders. These are Graves' disease and Hashimoto's thyroiditis. Hashimoto's thyroiditis (HT) is a common autoimmune disorder related to thyroid gland and it is associated with several pathogenic viruses and also strong presence of B-19 has been found. Regardless of viremia associated with these diseases persistent B-19 DNA has been found in thyroid tissues. The sample also strongly supports the presence of anti B-19 viral proteins (VP-1, VP-2, NS-1) [28, 35] Interestingly NF-KappaB up regulation and co-localization has been found with upregulated interleukin-6 in HT tissues [56]. Association of B-19 virus in Graves' diseases patients has been found but no significant co-relation can be obtained from this [40].

B-19 virus is actively involved in thyroid related malignancies. Specifically the virus has impact on the tumorigenesis of the thyroid cancer cells. B-19 virus has been detected in patient samples collected from individuals having papillary thyroid carcinoma, aplastic thyroid carcinoma. Nuclear and cytoplasmic localization of the viral capsid protein (VP-1 and VP-2). It is also interesting fact that, some adjacent non tumorous cells from same patient also shows shifting of the viral proteins inside the cells and they are having abnormal morphology. These cells have large nucleus and uncondensed chromatin compared to normal tissues. All these findings correlate the positive role of the B-19 virus in the tumor development [2].

\section{Host-pathogen interaction}

After reviewing the diseases manifestation of parvovirus B-19 now we will focus on its host pathogenic interactions. B-19 virus shows two types of infection inside the host cells. It may establish a successful productive infection and multiplication of the virus, leading to apoptosis or just an infection which is stable, and induction of immune response without any multiplication or productive virus production [46]. On the other hand, as B-19 infection is found in normal human adults and the virus may present for prolonged period of time even after the infection has been cured, so here the virus somehow maintains a latent condition inside the cell. As the B-19 virus is highly evolved, heat resistant and possess stable genomic structure without any lipid envelop the virus may remain silent without complete distortion with treatment and this status can be reactivated by some triggering situations like immune compression, hypoxia. In the feedback mechanism does these triggers or the immune response which is produced as a result of non-productive viral infection can reactivate the virus remains to be researched. In some of the above described diseases the B-19 virus has been found to be only associated with the diseases samples but they don't show any direct modulating activity rather they just 
triggers or boost up the diseases pathogenesis. Now these two types of pathogenesis will be discussed in detail.

\section{Constructive lytic cycle and associated cellular signaling}

The B-19 virus expresses two structural proteins VP1 and VP2. These are the viral capsid proteins and three nonstructural proteins NS1, NS11 and NS 7.5. These NS proteins mainly play important role in the host cell signaling modulation and apoptosis. There are several strategies that the virus follows for the attachment to the host cells. Globoside or $\mathrm{P}$ antigen mediated signaling is the main but there are several other mode of entry available like co-receptor (Ku80), integrin alpha 5 beta 1 or the antibody mediated routes [15].The $\mathrm{P}$ antigen route has been well characterized [13]. After the receptor mediated attachment of the viral capsid protein and $\mathrm{P}$ antigen of the host, the next step is the externalization of the VP-1 protein, which only acts for the internalization of the virus and then through endocytosis the virus enters inside the nucleus. Then the ssDNA is released and converted into double stranded replicative form. For this formation nicking of the ssDNA and NS1 protein is the main regulatory factor which directly binds with these ssDNA and replication is processed. On the other hand this intermediate replicative form synthesize pre-mRNAs and which is then by several conformational changes produces several viral mRNA and exported to cytoplasm and forms viral capsids and then transported back to the nucleus and packaged to form successful viral particles by the help of NS-1 protein and released through cell lysis. Except the P-antigen specific factor the erythroid progenitor cells depends on the EPO (glycoprotein based cytokine) mediated signaling for survival and replication by activating three downstream pathways, ERK, PI3 K and JAK-STAT5 [29]. Now for these viral strategies to be successful the host cellular defense mechanisms must be modulated or suppressed [58] Here virus induced DNA damage signaling is induced and late $S$ phase cell cycle arrest takes place which ultimately leads to extrinsic way of apoptosis. DNA damaged signaling is mediated by the up-regulation of ATM/ATR pathway proteins and TNF-alpha pathway involvement. Hypoxia is a mandatory factor for the lytic cycle of the virus $[20,46,55]$.

\section{Latent mechanistic with immunogenic response of $\mathrm{B} 19$ virus}

The host range is comparable for ssDNA virus with the dsDNA virus but the incidence of SSDNA virus is limited in case of humans and thus less information is also revealed regarding its' immunogenic potential inside the host. The few single stranded DNA binding protein like receptors can be targeted to chase the immune mechanism of SSDNA virus inside the human body, which can also be true for B-19 virus for its' less known immune potential information. As a direct interacting partner of B-19 virus and host immune system only the nonstructural protein 1 (NS1) has been reported. The exogenous type I -IFN induced STAT/ PIAS3 signaling by the interference of NS1 viral protein [20] leading to up-regulated inflammatory response and down-regulated antiviral host cell response. NS-1 protein and VP-1 mediated up-regulation of several inflammatory molecules like COX2, NF-kB, IL6 have been observed in this type of viral infection [31].

\section{Vaccine development against B-19 virus}

Observing the pathogenesis pattern of B-19 virus it can be said that it develops two kinds of infections inside the host cell. One is the active virus producing mechanism and another one is the persistent no virus producing mechanism. Both of these mechanism elicits clinical manifestations but in a different way. The available treatment modalities approaches both of the mechanisms in a same way, with the administration of normal antiviral antibiotics and intravenous immunoglobulin therapy (IVIG). The immunoglobulin therapy is the well-known single approach against the both types of B-19 associated diseases manifestation. Specifically IVIG treatments are okay for the immune related disorders, so when the virus evokes the immune system in case of the latent or persistent infection the approach is fine but when it comes to the lytic cycle there are no such precise treatment options available. Moreover, as in most of the cases of B-19 infection like other viral infection, when the symptoms appears in the patient, the virus almost disappears, thus neutralizing antibody treatment is not an better option. Focus should be given on developing cellular and innate immunity and for that vaccine development is a better option, with advanced support of CD8 $+\mathrm{T}$ cell response which is the only one possible cell mediated weapon to respond against the viral infection and reported so far in various studies [10, 15].

\section{First generation baculoviral expression system and adjuvant based vaccines}

Till date research for the therapeutic approach against the B-19 pathogenesis, is directed towards the vaccine development. The difficulties for the clinical study and development of vaccine are due to the unavailability of viral antigens. The viremia is almost absent in the infected patients when the symptoms start to appear. There is no such good cell line model available and also B-19 virus 
infected stable animal model is very difficult to have. But the story begins with the discovery of B-19 virus like particle producing Baculovirus expression system. In this system, empty capsid consisting of only the two viral structural proteins (VP-1 and VP-2) is enough to produce host serum B-19 viral mimics and they can also produce neutralizing antibodies [27]. After this discovery of B-19 expression system, researchers started to develop candidate vaccines for B-19. Few research invented Baculovirus insect cell based vaccine that is composed maximally of VP-1 which is thought to be the major protein for the production of the neutralizing antibodies in patient's serum [6]. There are few researches on different combinational portion of VP-1 and VP-2 derived B-19 expression system. A research by Eliza Zufi demonstrate a small peptide of 60-100 amino acids from the VP-1 protein sequence has the maximum antibody producing ability and can be used as peptide vaccine [62]. Later MEDImmune manufactured vaccine MEDI-491 composed of VP-1 and VP-2 protein has been found as vaccine against B-19 virus but this vaccine along with alluminium hydroxide adjuvant shows low antibody productivity against the virus. Then emulsion based adjuvant found to be potent and the baculoviral expression system based vaccine MEDI-491 was assembled with emulsion based adjuvant MF59C.1 administered into host cell and found as a safe, well tolerated and moderately potent vaccine against B-19 infection to produce antibody [5].

\section{The second generation of B-19 viral vaccines}

The next generation vaccines are based on bacterial expression systems. The previously described ones are based on insect cell expressions that is the baculoviral system is induced in insect cells and which is administered to human body and thus it induces reactive symptoms in the host like, rash, swelling, headache, gastrointestinal problems etc. so the baculovirus vaccines in clinical trials also stopped for these adverse effects. More over other disadvantages include, these vaccines are composed of two viral proteins recombinant expressing baculoviral cells, VP-1 and VP-2 and the expression of these two proteins are adjusted by the different combinational ratios of two recombinants and it creates a confusing strategy without any specific equation. On the other hand in general the degree of antibody productivity varies for baculoviral vaccines. Considering these facts, the next generation vaccines are expressed in prokaryotic system. An interesting cost effective expression system in Saccharomyces cerevisiae has been reported where the VP-2 proteins has been considered only which can produce B-19 virus like particle without the presence of VP-1 which has been considered as the major viral protein and used at high percentage in baculoviral vaccine [30]. Next based on this finding much upgraded vaccine having only one recombinant plasmid expressing both VP-1 and VP-2 in a restricted and equal expressing ratio has been transformed to Saccharomyces cerevisiae [12]. Later this vaccine was administered and tested in a sickle cell mice model with respiratory infection and proved as permissible one [41].

It can be concluded that development of new vaccine considering its maximum potential and minimum reactivity has been considered so far but the thing which is ignored that, these approaches must be tested in a B-19 virus infected model system. In all the above vaccines were tested in healthy individual and the response were compared with the patients conditions and hypothetically it is proposed that they may be potent enough but to apply it in real B-19 infected patients it must be clinically proved in infected model system.

\section{Concluding remarks}

After reviewing the diseases manifestation and its related pathogenesis, the following questions may come into mind.

\section{Determining factors for infection}

The virus causes mainly two types to diseases manifestation due to its two mode of pathogenesis. In its productive lytic infectious mode it leads to clinical manifestations like fifth diseases, aplastic anemia, hydroph fetalis, etc. and on the other hand, the non- productive, persistent latent infection evokes the immune system and leads to active immune response that can be linked with several inflammatory diseases like meningoencephalitis, cardiomyopathy, rheumatoid arthiritis, vasculitis etc. Now this discrimination may be caused by the viral tropism.

The virus mainly infects human erythroid progenitor cells expressing globoside or P antigen and successfully multiply there after entry due to the mechanism of the eryothro protein. Parallely not all the p-antigen receptor representing cells are susceptible to B-19 virus. Here comes the other kind of infections associated with non erythroid progenitor cells showing only immune response are associated with the non globoside entry and followed by co-receptor mediated or antibody mediated pathway for entry and that cannot establish successful multiplication. On the other hand this tropism can cause the resistance of the virus automatically for the non $\mathrm{P}$ antigen expressing cells.

Another determining factor may be the hypoxia. It has been observed that B-19 virus replicative cells cannot produce productive virions under ex vivo conditions. The erythroid progenitor cells in the bone marrow are under 
Fig. 1 Overview of B-19V infection, disease manifestation and available therapeutic strategy

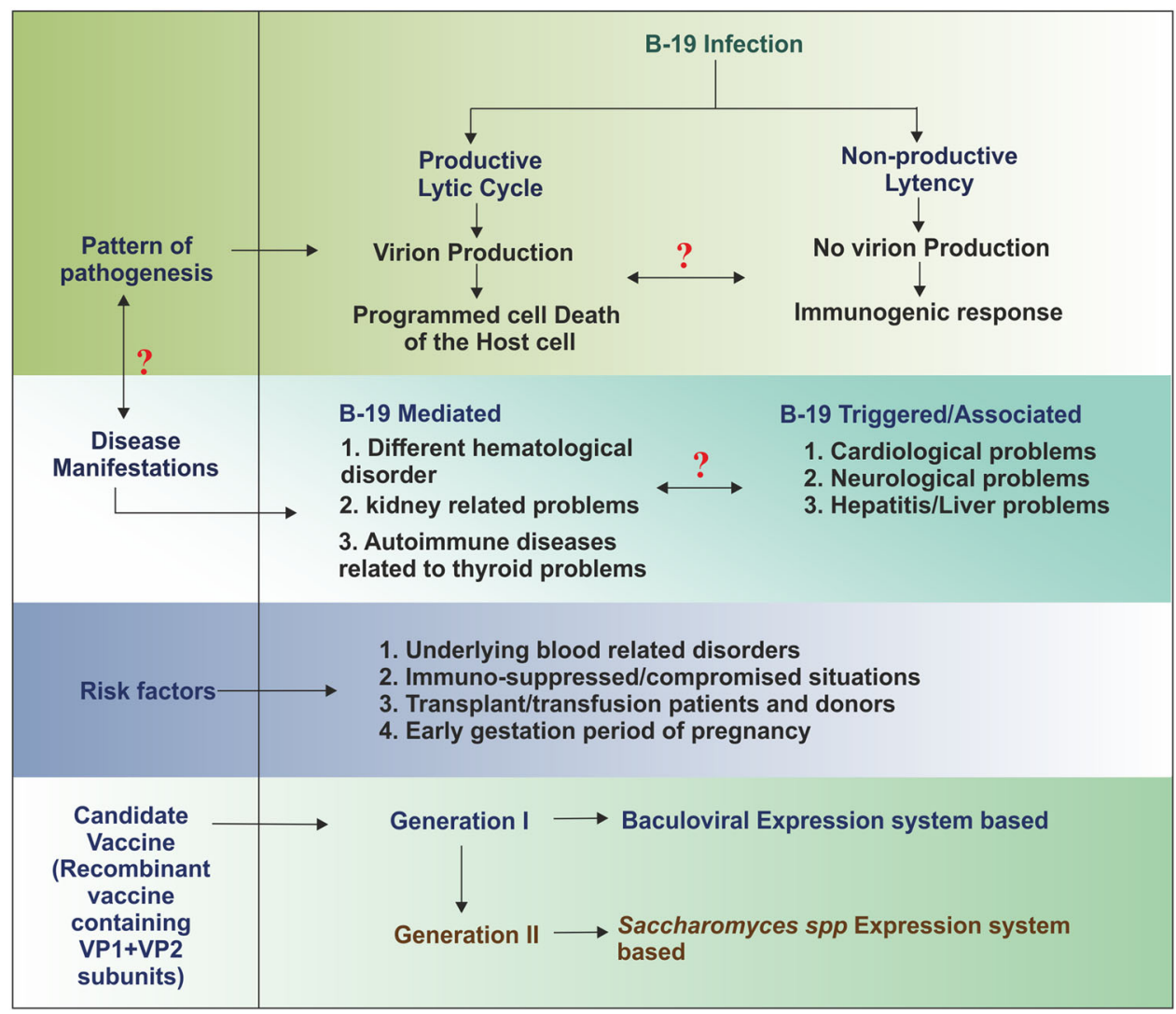

low oxygenic environment and that condition enhances the virus production and gene expression in artificial environment also.

The next determining factor of B-19 virus may be the additional underlying health conditions like haemolytic and immune system disorders. It has been observed from the above study that all the diseases manifestation related to B-19 virus pathogenesis becomes severe and even fetal when it is associated with any kind of hemolytic disorders immunedisturbed/suppressed, pregnancy, and transplant patients.

\section{Attention to be paid for B-19 virus}

The B-19 virus infection has been seen in non-erythroid cells following alternative globoside independent pathways. This emerging nature of the viral pathogenesis towards different cellular origins and tissue specificity indicates the evolutionary nature of the virus and new diseases associations. This alternative pathway is the latent one and it may also become dangerous in terms of its long term viral persistency and reactivation. The co-existence of the virus with other pathogens shows synergistic effect of the virus in the diseases pathogenesis. B-19 virus is found to be associated with cancer without any other association (thyroid carcinoma). Thus there is a possibility of having cell modulatory oncogenic property. The pregnant women, children with hemolytic disorders, immune compromised patients and blood transplanted and organ transplanted patients comes under high risk groups.

Parvovirus B-19 as a single stranded DNA virus is the single member of its family in causing infection to humans, but considering the above study it is clearly revealed that it can directly cause, trigger or may be associated with a wide range of diseases pull, and except the common antiviral and antibody based drugs, vaccine development has been considered currently as advanced therapeutic strategy which has clearly depicted in Fig. 1. The relation of viral pathogenesis with specific diseases association has not been studied so far and this is an area of concern which has to be emphasized to understand the pathogen and its' further control. Thus, if we consider the evolutionary aspect of this virus, that is emerging and might be threatening in future. As a preventive measure, first of all a well-developed early screening system should be implied. The highrisk groups like pregnant women, child, immunocompromised and transplant/transfused donor patients should be included in a basic and regular screening system with early detection and vaccination process. Lastly in terms of research the molecular pathogenesis of the virus in specific diseases model have to be understood. Then therapeutic strategy targeting on the molecular pathways should be 
searched and parallely immunotherapy and vaccine development must be emphasized to have productive results.

\section{Compliance with ethical standards}

Conflict of interest There is no conflict of interest.

\section{References}

1. Abkowitz JL, Brown KE, Young NS, Kovach NL, Wood RW, Green SW. Clinical relevance of parvovirus B19 as a cause of anemia in patients with human immunodeficiency virus infection. J Infect Dis. 1997;176(1):269-73. https://doi.org/10.1086/517264 (Published Online First: Epub Date).

2. Adamson LA, Fowler LJ, Clare-Salzler MJ, Hobbs JA. Parvovirus B19 infection in hashimoto's thyroiditis, papillary thyroid carcinoma, and anaplastic thyroid carcinoma. Thyroid. 2011;21(4):411-7. https://doi.org/10.1089/thy.2010.0307 (Published Online First: Epub Date).

3. Alberti L, Loffi M, Fragasso G, Spoladore R, Ballarotto C, Margonato A. Acute heart failure caused by parvovirus B-19 myocarditis treated with human immunoglobulin. Case Rep Cardiol. 2012. https://doi.org/10.1155/2012/180871 (Published Online First: Epub Date).

4. Baek CH, Kim H, Yang WS, Han DJ, Park SK. Risk factors and long-term outcomes of parvovirus B19 infection in kidney transplant patients. Transpl Infect Dis. 2017. https://doi.org/10. 1111/tid.12754 (Published Online First: Epub Date).

5. Ballou WR, Reed JL, Noble W, Young NS, Koenig S. Safety and immunogenicity of a recombinant parvovirus B19 vaccine formulated with MF59C.1. J Infect Dis. 2003;187(4):675-8. https:// doi.org/10.1086/368382 (Published Online First: Epub Date).

6. Bansal GP, Hatfield JA, Dunn FE, et al. Candidate recombinant vaccine for human B19 parvovirus. J Infect Dis. 1993;167(5):1034-44.

7. Barah F, Whiteside S, Batista S, Morris J. Neurological aspects of human parvovirus B19 infection: a systematic review. Rev Med Virol. 2014;24(3):154-68. https://doi.org/10.1002/rmv.1782 (Published Online First: Epub Date).

8. Bihari C, Rastogi A, Saxena P, et al. Parvovirus b19 associated hepatitis. Hepat Res Treat. 2013;2013:472027. https://doi.org/10. 1155/2013/472027 (Published Online First: Epub Date).

9. Bonvicini F, Gallinella G, Musiani M, Zerbini M, Marinacci G, Pajno MC. Meningoencephalitis with persistent parvovirus B19 infection in an apparently healthy woman. Clin Infect Dis. 2008;47(3):385-7. https://doi.org/10.1086/589863 (Published Online First: Epub Date).

10. Burton DR. Antibodies, viruses and vaccines. Nat Rev Immunol. 2002;2(9):706-13. https://doi.org/10.1038/nri891 (Published Online First: Epub Date).

11. Çetin M, Özyürek E, Aslan D, Uçkan D. Parvovirus B19 infection associated with severe aplastic anemia in an immunocompetent patient AU-Yetgin, Sevgi. Pediatr Hematol Oncol. 2004;21(3):223-6. https://doi.org/10.1080/08880010490276935 (Published Online First: Epub Date).

12. Chandramouli S, Medina-Selby A, Coit D, et al. Generation of a parvovirus B19 vaccine candidate. Vaccine. 2013;31(37):3872-8. https://doi.org/10.1016/j.vaccine.2013.06.062 (Published Online First: Epub Date).

13. Chen AY, Guan W, Lou S, Liu Z, Kleiboeker S, Qiu J. Role of erythropoietin receptor signaling in parvovirus B19 replication in human erythroid progenitor cells. J Virol. 2010;84(23):12385-96. https://doi.org/10.1128/jvi.01229-10 (Published Online First: Epub Date).

14. Christensen LS, Madsen TV, Barfod T. Persistent erythrovirus B19 urinary tract infection in an HIV-positive patient. Clin Microbiol Infect. 2001;7(9):507-9. https://doi.org/10.1046/j. 1198-743x.2001.00299.x (Published Online First: Epub Date).

15. Corcoran A, Doyle S. Advances in the biology, diagnosis and host-pathogen interactions of parvovirus B19. J Med Microbiol. 2004;53(Pt 6):459-75. https://doi.org/10.1099/jmm.0.05485-0 (Published Online First: Epub Date).

16. de Haan TR, de Jong EP, Oepkes D, Vandenbussche FP, Kroes AC, Walther FJ. Infection with human parvovirus B19 ('fifth disease') during pregnancy: potential life-threatening implications for the foetus. Ned Tijdschr Geneeskd. 2008;152(21):1185-90.

17. Eid AJ, Brown RA, Patel R, Razonable RR. Parvovirus B19 infection after transplantation: a review of 98 cases. Clin Infect Dis. 2006;43(1):40-8. https://doi.org/10.1086/504812 (Published Online First: Epub Date).

18. Ferry $\mathrm{T}$, Hirschel $\mathrm{B}$, Dang $\mathrm{T}$, et al. Infrequent replication of parvovirus B19 and erythrovirus genotypes 2 and 3 among HIVinfected patients with chronic anemia. Clin Infect Dis. 2010;50(1):115-8. https://doi.org/10.1086/649004 (Published Online First: Epub Date).

19. Frickhofen N, Abkowitz JL, Safford M, et al. Persistent B19 parvovirus infection in patients infected with human immunodeficiency virus type 1 (HIV-1): a treatable cause of anemia in AIDS. Ann Intern Med. 1990;113(12):926-33.

20. Ganaie SS, Qiu J. Recent advances in replication and infection of human parvovirus B19. Front Cell Infect Microbiol. 2018;8:166. https://doi.org/10.3389/fcimb.2018.00166 (Published Online First: Epub Date).

21. Giorgio E, De Oronzo MA, Iozza I, et al. Parvovirus B19 during pregnancy: a review. J Prenat Med. 2010;4(4):63-6.

22. Gratacos E, Torres PJ, Vidal J, et al. The incidence of human parvovirus B19 infection during pregnancy and its impact on perinatal outcome. J Infect Dis. 1995;171(5):1360-3.

23. Heegaard ED, Brown KE. Human parvovirus B19. Clin Microbiol Rev. 2002;15(3):485-505. https://doi.org/10.1128/cmr.15.3. 485-505.2002 (Published Online First: Epub Date).

24. Jain P, Jain A, Khan DN, Kumar M. Human parvovirus B19 associated dilated cardiomyopathy. BMJ Case Rep. 2013;2013:bcr2013010410. https://doi.org/10.1136/bcr-2013010410 (Published Online First: Epub Date).

25. Jain A, Jain P, Kumar A, Prakash S, Khan DN, Kant R. Incidence and progression of Parvovirus B19 infection and molecular changes in circulating B19V strains in children with haematological malignancy: a follow up study. Infect Genet Evol. 2018;57:177-84. https://doi.org/10.1016/j.meegid.2017.11.021 (Published Online First: Epub Date).

26. Jain A, Jain P, Prakash S, Khan DN, Kumar A, Kant R. Prevalence of Parvovirus B19V in Hematological Malignancies and Chronic Anemia. Indian J Pediatr. 2018;85(1):77-8. https://doi. org/10.1007/s12098-017-2428-8 (Published Online First: Epub Date).

27. Kajigaya S, Fujii H, Field A, et al. Self-assembled B19 parvovirus capsids, produced in a baculovirus system, are antigenically and immunogenically similar to native virions. Proc Natl Acad Sci USA. 1991;88(11):4646-50.

28. Lehmann HW, Lutterbuse N, Plentz A, et al. Association of parvovirus B19 infection and Hashimoto's thyroiditis in children. Viral Immunol. 2008;21(3):379-83. https://doi.org/10.1089/vim. 2008.0001 (Published Online First: Epub Date).

29. Lodish HF, Ghaffari S, Socolovsky M, Tong W, Zhang J. Intracellular signaling by the erythropoietin receptor 2009:155-74. 
30. Lowin T, Raab U, Schroeder J, Franssila R, Modrow S. Parvovirus B19 VP2-proteins produced in Saccharomyces cerevisiae: comparison with VP2-particles produced by baculovirusderived vectors. J Vet Med B Infect Dis Vet Public Health. 2005;52(7-8):348-52. https://doi.org/10.1111/j.1439-0450.2005. 00871.x (Published Online First: Epub Date).

31. Lu J, Zhi N, Wong S, Brown KE. Activation of synoviocytes by the secreted phospholipase A2 motif in the VP1-unique region of parvovirus B19 minor capsid protein. J Infect Dis. 2006;193(4):582-90. https://doi.org/10.1086/499599 (Published Online First: Epub Date).

32. Mammen K, Varghese J, Shah V, Tuli A. Recurrent parvovirus B19 infection in postrenal transplant recipient. Indian J Transpl. 2018;12(3):207-9. https://doi.org/10.4103/ijot.ijot_27_17 (Published Online First: Epub Date).

33. Modrow S. Parvovirus B19: the causative agent of dilated cardiomyopathy or a harmless passenger of the human myocard? Ernst Schering Res Found Workshop. 2006;55:63-82.

34. Mogensen TH, Jensen JMB, Hamilton-Dutoit S, Larsen CS. Chronic hepatitis caused by persistent parvovirus B19 infection. BMC Infect Dis. 2010;10:246. https://doi.org/10.1186/14712334-10-246 (Published Online First: Epub Date).

35. Mori K, Munakata Y, Saito T, et al. Intrathyroidal persistence of human parvovirus B19 DNA in a patient with Hashimoto's thyroiditis. J Infect. 2007;55(2):e29-31. https://doi.org/10.1016/j. jinf.2007.05.173 (Published Online First: Epub Date).

36. Mühlemann B, Margaryan A, Damgaard PB, et al. Ancient human parvovirus B19 in Eurasia reveals its long-term association with humans. Proc Natl Acad Sci USA. 2018;115(29):7557-62.

37. Norja P, Eis-Hübinger AM, Söderlund-Venermo M, Hedman K, Simmonds P. Rapid sequence change and geographical spread of human parvovirus B19: comparison of B19 virus evolution in acute and persistent infections. J Virol. 2008;82(13):6427-33.

38. Oliveira GM, Pascoal-Xavier MA, Moreira DR, et al. Detection of cytomegalovirus, herpes virus simplex, and parvovirus b19 in spontaneous abortion placentas. The journal of maternal-fetal \& neonatal medicine: the official journal of the European Association of Perinatal Medicine, the Federation of Asia and Oceania Perinatal Societies, the International Society of Perinatal Obstet. 2017:1-8. https://doi.org/10.1080/14767058.2017.1391778. (Published Online First: Epub Date).

39. Osaki M, Matsubara K, Iwasaki T, et al. Severe aplastic anemia associated with human parvovirus B19 infection in a patient without underlying disease. Ann Hematol. 1999;78(2):83-6.

40. Page C, Hoffmann TW, Benzerdjeb N, Duverlie G, Sevestre H, Desailloud R. Detection of erythrovirus B19 in thyroidectomy specimens from Graves' disease patients: a case-control study. J Med Virol. 2013;85(8):1414-9. https://doi.org/10.1002/jmv. 23595 (Published Online First: Epub Date).

41. Penkert RR, Young NS, Surman SL, et al. Saccharomyces cerevisiae-derived virus-like particle parvovirus B19 vaccine elicits binding and neutralizing antibodies in a mouse model for sickle cell disease. Vaccine. 2017;35(29):3615-20. https://doi.org/10. 1016/j.vaccine.2017.05.022 (Published Online First: Epub Date).

42. Pinto ACS, Covas DT, Slavov SN, Kashima S. Human parvovirus B19: general considerations and impact on patients with sicklecell disease and thalassemia and on blood transfusions. FEMS Immunol Med Microbiol. 2011;62(3):247-62. https://doi.org/10. 1111/j.1574-695x.2011.00819.x (Published Online First: Epub Date).

43. Qian XH, Zhang GC, Jiao XY, et al. Aplastic anaemia associated with parvovirus B19 infection. Arch Dis Child. 2002;87(5):436-7. https://doi.org/10.1136/adc.87.5.436 (Published Online First: Epub Date).
44. Raturi G, Kaur P, Kaur G. Seroprevalence of human parvovirus B19 amongst North Indian blood donors-Do current donor testing guidelines need a relook? Transfus Apher Sci. 2018;57(5):646-50. https://doi.org/10.1016/j.transci.2018.07.017 (Published Online First: Epub Date).

45. Richards M (2015) Disseminated parvovirus infection with interstitial pneumonia and a pericardial effusion in an adult allogeneic stem cell transplant patient.

46. Servant-Delmas A, Lefrère J-J, Morinet F, Pillet S. Advances in human B19 erythrovirus biology. J Virol. 2010;84(19):9658-65. https://doi.org/10.1128/jvi.00684-10 (Published Online First: Epub Date).

47. Slavov SN, Kashima S, Pinto AC, Covas DT. Human parvovirus B19: general considerations and impact on patients with sicklecell disease and thalassemia and on blood transfusions. FEMS Immunol Med Microbiol. 2011;62(3):247-62. https://doi.org/10. 1111/j.1574-695x.2011.00819.x (Published Online First: Epub Date).

48. Sokal EM, Melchior M, Cornu C, et al. Acute parvovirus B19 infection associated with fulminant hepatitis of favourable prognosis in young children. Lancet (London, England). 1998;352(9142):1739-41. https://doi.org/10.1016/s01406736(98)06165-0 (Published Online First: Epub Date).

49. Stamenković GG, Ćirković VS, Šiljić MM, et al. Substitution rate and natural selection in parvovirus B19 OPEN. Sci Rep. 2016;6(35759):1-9.

50. Staroselsky A, Klieger-Grossmann C, Garcia-Bournissen F, Koren G. Exposure to fifth disease in pregnancy. Canadian Family Physician Medecin de Famille Canadien. 2009;55(12):1195-8.

51. Tavakoli A, Monavari SH, Mollaei H, et al. Frequency of human parvovirus B19 among patients with respiratory infection in Iran. Med J Islamic Repub Iran. 2018;32:38. https://doi.org/10.14196/ mjiri.32.38 (Published Online First: Epub Date).

52. Tijssen P, Penzes JJ, Yu Q, Pham HT, Bergoin M. Diversity of small, single-stranded DNA viruses of invertebrates and their chaotic evolutionary past. J Invertebr Pathol. 2016;140:83-96. https://doi.org/10.1016/j.jip.2016.09.005 (Published Online First: Epub Date).

53. Verdonschot J, Hazebroek M, Merken J, et al. Relevance of cardiac parvovirus B19 in myocarditis and dilated cardiomyopathy: review of the literature. Eur J Heart Fail. 2016;18(12):1430-41. https://doi.org/10.1002/ejhf.665 (Published Online First: Epub Date).

54. Waldman M, Kopp JB. Parvovirus B19 and the kidney. Clin J Am Soc Nephrol. 2007;2(Supplement 1):S47-56. https://doi.org/ 10.2215/cjn.01060307 (Published Online First: Epub Date).

55. Wan Z, Zhi N, Wong S, et al. Human parvovirus B19 causes cell cycle arrest of human erythroid progenitors via deregulation of the E2F family of transcription factors. J Clin Investig. 2010;120(10):3530-44. https://doi.org/10.1172/jci41805 (Published Online First: Epub Date).

56. Wang J, Zhang W, Liu H, et al. Parvovirus B19 infection associated with Hashimoto's thyroiditis in adults. J Infect. 2010;60(5):360-70. https://doi.org/10.1016/j.jinf.2010.02.006 (Published Online First: Epub Date).

57. Wardeh A, Marik P. Acute lung injury due to parvovirus pneumonia. J Intern Med. 1998;244(3):257-60.

58. $\mathrm{Xu} \mathrm{P}$, Yun Chen A, Ganaie $\mathrm{S}$, et al. The nonstructural protein $11-\mathrm{kDa}$ of human parvovirus B19 facilitates viral DNA replication by interacting with Grb2 through its proline-rich motifs 2018.

59. Yanagihara T, Hamano S, Otsubo K, et al. Acute respiratory failure in a healthy adult with human parvovirus B19 infection, 2017. 
60. Yoto Y, Kudoh T, Haseyama K, Suzuki N, Chiba S. Human parvovirus B19 infection associated with acute hepatitis. Lancet (London, England). 1996;347(9005):868-9.

61. Zeckanovic A, Perovnik M, Jazbec J, Kavcic M. Spectrum of Parvovirus B19 Infection Presentations in Children with Underlying Hemato-oncologic Disorders: A Case Series. Klin Padiatr. 2018;230(6):330-2. https://doi.org/10.1055/a-0594-9362 (Published Online First: Epub Date).
62. Zuffi E, Manaresi E, Gallinella G, et al. Identification of an immunodominant peptide in the parvovirus B19 VP1 unique region able to elicit a long-lasting immune response in humans. Viral Immunol. 2001;14(2):151-8. https://doi.org/10.1089/ 088282401750234529 (Published Online First: Epub Date).

Publisher's Note Springer Nature remains neutral with regard to jurisdictional claims in published maps and institutional affiliations. 